Article

\title{
Gelatin Hydrolysate Hybrid Nanoparticles as Soft Edible Pickering Stabilizers for Oil-In-Water Emulsions
}

\author{
Zhongyao Du and Pengjie Wang * \\ Beijing Advanced Innovation Center for Food Nutrition and Human Health, College of Food Science \& \\ Nutritional Engineering, China Agricultural University, Beijing 10036, China; duzhongyao@cau.edu.cn \\ * Correspondence: wpj1019@cau.edu.cn; Tel.: +86-010-6273-6348
}

Academic Editor: Tibor Pasinszki

Received: 3 December 2019; Accepted: 15 January 2020; Published: 17 January 2020

\begin{abstract}
The aim of this study was to fabricate edible gelatin enzymic digest (GED) based gel particles that can stabilize oil-in-water $(\mathrm{O} / \mathrm{W})$ microemulsions. The gel particles were generated by covalent crosslinking, with genipin, the individual protein molecules within tannic acid-induced gelatin hydrolysate (GED-TA) particles. The ability of the genipin-treated GED-TA (GP-GED-TA) to stabilize emulsions was evaluated by Turbiscan analysis and droplet-size changes. For comparison, gelatin hydrolysate (GE) and tannic acid-induced gelatin hydrolysate particles (GED-TA) were used as controls. The mean diameters of GED, GED-TA, and GP-GED-TA particles were $0.68 \pm 0.1 \mathrm{~nm}, 66.2 \pm 8.4 \mathrm{~nm}$, and $66.9 \pm 7.2 \mathrm{~nm}$, respectively. Nanomechanic analysis using atomic force microscopy(AFM) indicated the average Young's modulu of the GP-GED-TA particles was $760.8 \pm 112.0 \mathrm{Mpa}$, indicating the GP-GED-TA were soft particles. The Turbiscan stability indexes (lower values indicate a more stable emulsion) of the emulsions stabilized with GED, GED-TA, and GP-GED-TA, after storage for three days, were $28.6 \pm 1.5,19.3 \pm 4.8$, and $4.4 \pm 1.3$, respectively. After one, or 60 days of storage, the volume-weighted mean diameters $\left(D_{[4,3]}\right)$ of oil droplets stabilized by GP-GED-TA were $1.19 \pm 0.11 \mu \mathrm{m}$ and $1.18 \pm 0.1 \mu \mathrm{m}$, respectively. The $\mathrm{D}_{[4,3]}$ of oil droplets stabilized by GED-TA, however, increased from $108.3 \pm 5.1 \mu \mathrm{m}$ to $164.3 \pm 19.1 \mu \mathrm{m}$ during the storage. Overall, the GP-GED-TA gel particles have considerable potential for stabilization of $\mathrm{O} / \mathrm{W}$ emulsions in food products.
\end{abstract}

Keywords: edible pickering stabilizer; emulsifying property; gelatin hydrolysate hybrid; soft gel particles

\section{Introduction}

Oil-in-water $(\mathrm{O} / \mathrm{W})$ emulsions are systems consisting of oil phase dispersed in aqueous phase [1]. They are used in many food products, such as salad dressings and mayonnaise [2,3]. Conventionally, $\mathrm{O} / \mathrm{W}$ emulsions are prepared and stabilized by surfactants, but recent reports have focused on O/W Pickering emulsions, which are stabilized by nanoparticles [4-6]. Particles effectively inhibit the flocculation or coalescence of oil droplets in emulsions, by surrounding the oil droplets and keeping them apart $[7,8]$. In addition, the adsorption energy of a particle at the oil-water interface is much higher than its thermal energy. Therefore, particles are irreversibly adsorbed at the oil-water interface $[9,10]$.

Particles for stabilizing Pickering emulsions can be classified as inorganic solid particles and organic particles [11-14]. Inorganic solid particles are usually not applicable in the food industry. Currently, many edible organic particles for stabilizing $\mathrm{O} / \mathrm{W}$ emulsions have been developed, including starch particles [15], cellulose particles [16], chitin particles [17], and protein colloidal particles [18]. Soft protein particles have gained the most attention $[19,20]$ because they have dangling protein chains on their surfaces that give them an enhanced ability to accumulate at the interface, similar to protein molecules. Once adsorbed onto the interface, they form a viscoelastic layer with higher mechanical 
strength than that of rigid particles (such as cellulose or chitin particles). Therefore, soft protein particles have better emulsifying activity and emulsion stabilization [21].

To date, different protein-based particle stabilizers have been reported, including zein [22], whey protein [18], peanut protein [23], and soybean protein [24]. However, they are usually rigid particles, because they are generally prepared by heat treatment, or antisolvent precipitation, resulting in highly crosslinked polymer-based particles [25]. Therefore, the development of edible soft particles could have wide application in food emulsion-based products.

Gelatin is an inexpensive food additive which is produced by collagen hydrolysis. Several instances of the preparation of soft gelatin Pickering particles have been reported. Tan et al. developed gelatin Pickering particles, using glutaraldehyde as a crosslinker [26]. However, glutaraldehyde is toxic which restricts its application in food emulsions. Feng et al. prepared gelatin particles by a two-step desolvation procedure, using genipin as a crosslinking agent [27]. Genipin is a natural crosslinking agent extracted from Gardenia jasminoides E. which has low toxicity to the human body. However, the particle diameter produced by this method was larger than $350 \mathrm{~nm}$. This means that these particles could only stabilize oil droplets larger than $3.5 \mu \mathrm{m}$, since the diameter of particle should be at least one order of magnitude smaller than the targeted oil droplets [28].

In this study, we aimed to develop edible soft particles that could stabilize oil droplets smaller than $1.5 \mu \mathrm{m}$. The particles were composed of gelatin enzymatic digests (GED) and tannic acid (TA) (Figure 1), which are commercially readily available. The high binding affinity between GED and TA favors the formation of colloidal particles [29]. The formation of GED-TA particles is associated with hydrogen bonding between the hydroxyl groups in TA and the hydroxyproline residues in GED [29]. However, the GED-TA particles are noncovalent crosslinking, which could be easily dissociated at the oil-water interfaces. In this case, the introduction of covalent crosslinking agent could fabricate to form particles that cannot dissociate at the interfaces. Therefore, we used an edible covalent crosslinking agent, genipin, to further crosslink the GED-TA particles. Partly crosslinking the amino groups within the particles with genipin has generated stable Pickering stabilizers [30]. Therefore, in this study, we aimed to create edible gel particles, smaller than $150 \mathrm{~nm}$, from GED and TA, and to test their ability to stabilize oil droplets in $\mathrm{O} / \mathrm{W}$ emulsions.
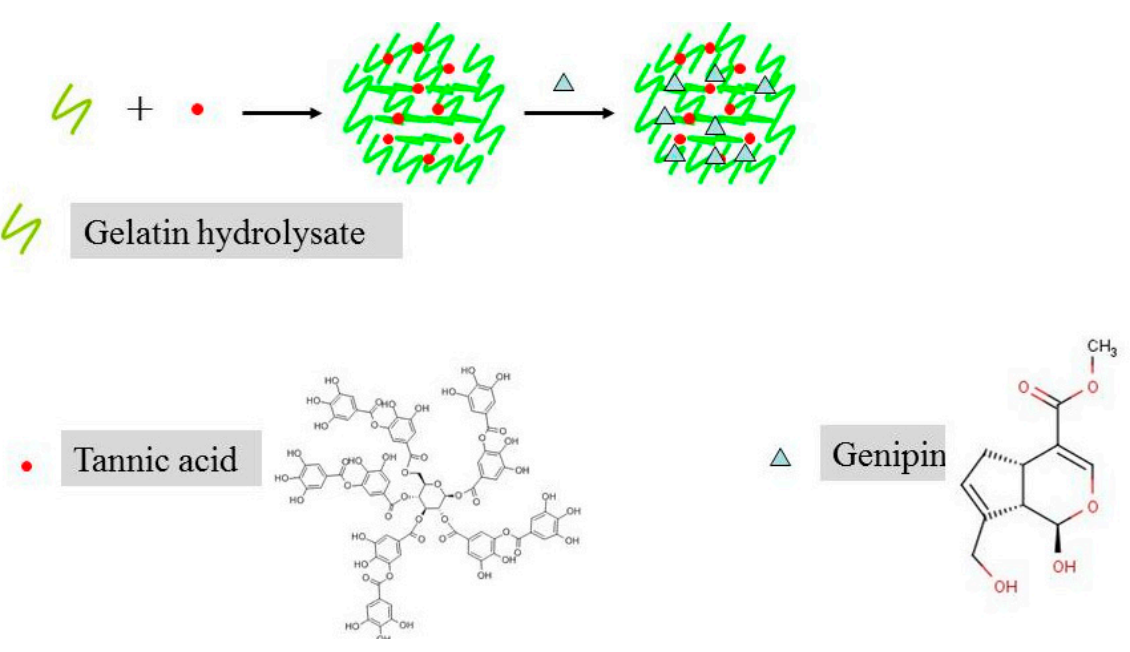

Figure 1. Schematic diagram of the preparation of genipin-treated tannic acid-induced gelatin hydrolysate (GP-GED-TA) gel particles.

\section{Results}

\subsection{Characterization of Gel Particles}

The formation of crosslinks in the genipin-treated tannic acid-induced gelatin hydrolysate (GP-GED-TA) particles was verified using a dissociation agent. In the presence of $8 \mathrm{~mol} \mathrm{~L}^{-1}$ urea 
solution, particles stabilized only by noncovalent bonds dissociate into individual molecules [31,32]. However, covalently crosslinked samples do not dissociate into individual molecules [33]. The mean diameter of GED-TA particles dispersed in water was $66.2 \pm 8.4 \mathrm{~nm}(n=3)$, but decreased to $0.69 \pm 0.1 \mathrm{~nm}$ in the presence of $8 \mathrm{~mol} \mathrm{~L}^{-1}$ urea (Figure 2). The GED-TA particles clearly dissociated into individual GED molecules in urea solution, as their particle size $(0.69 \pm 0.1 \mathrm{~nm}$ vs. $0.68 \pm 0.1 \mathrm{~nm})$ was identical to GED in water. However, for GP-GED-TA, the particle size in urea solution was not significantly different from that in pure water $(70.9 \pm 12.1 \mathrm{~nm}$ VS. $66.9 \pm 7.2 \mathrm{~nm})$. This confirmed that GP-GED-TA particles could maintain their integrity and were resistant to dissociation into individual GED molecules at oil-water interfaces.
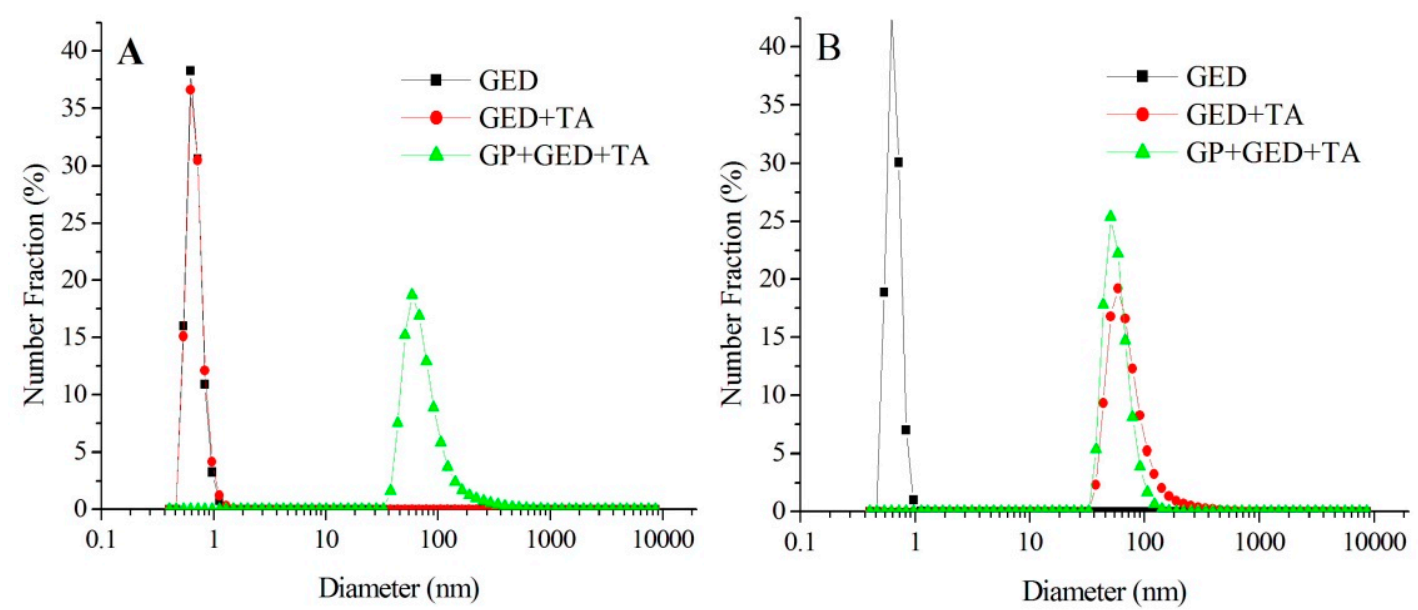

Figure 2. Size distribution curves, from zeta potential measurements, of particles in $8 \mathrm{~mol} \mathrm{~L}^{-1}$ urea solutions (A) or in water (B).

The morphologies of the particles were observed by transmission electron microscopy (TEM) in Figure 3. It was confirmed that the particles are gspherical, with a diameter lower than the light scattering data. This is because the GP-GED-TA particles dehydrated during TEM sample preparation in in atmosphere environment.

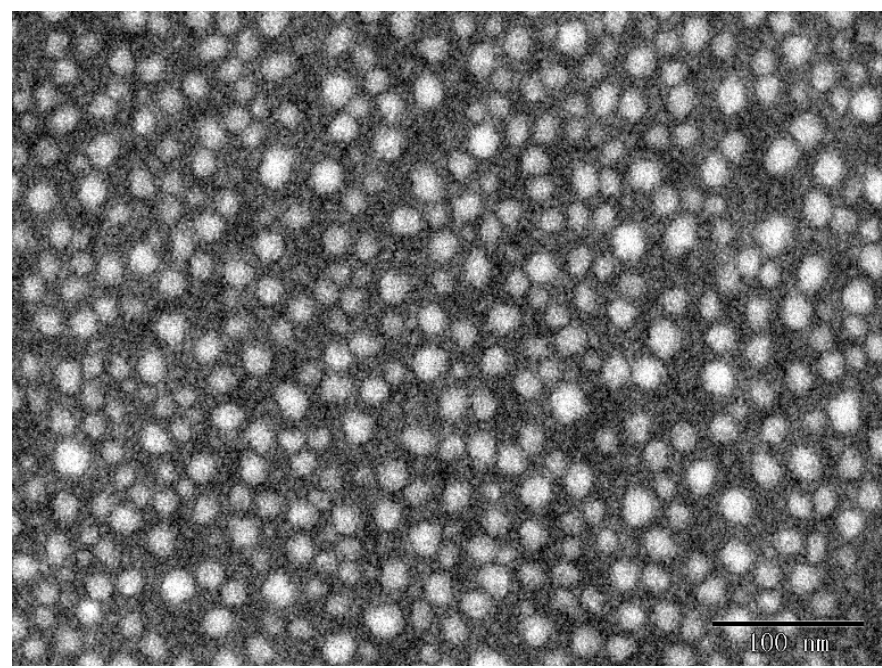

Figure 3. Transmission electron microscopy (TEM) images of GP-GED-TA particles. The scale bar is $100 \mathrm{~nm}$.

Nanomechanic analysis using peak-force quantitative nanomechanical atomic force microscopy (AFM) indicated the average Young's modulus of the GP-GED-TA particles was 311.5 $\pm 80.2 \mathrm{MPa}$ ( $n=35$, calculated from arithmetic mean value in Figure 4$)$. This value was similar to the results of 
protein-based particles [34,35], but larger than the inorganic particles [36,37]. This indicated the GP-GEDTA particles were soft. From the AFM results, the GP-GED-TA was proven to be soft particles, which have advantages over rigid solid particles in stabilizing the oil droplets. First, it has dangling polymer chains on the surfaces which have the ability of anchoring at the interfaces. This endowed the GP-GED-TA particles higher emulsifying capacity than solid hard particles. Secondly, the particles could deform and flatten at the oil-water interface, which could, thus, form a network at the interface [12]. This favors the formation of interfacial film with higher elasticity and strength as compared with hard particles. Therefore, the covalently crosslinked GP-GED-TA particles could have better emulsifying stability than hard particles.

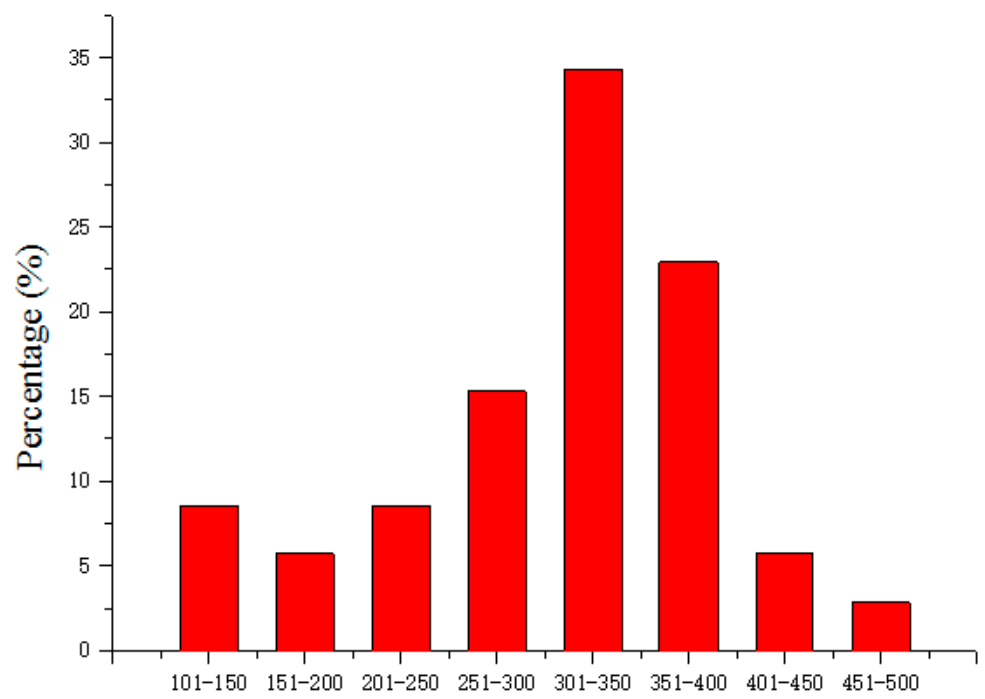

DMT Modulus (MPa)

Figure 4. Distribution of the Young's modulus of GP-GED-TA particles in Derjaguin-Müller-Toporov (DMT) modulus channels.

\subsection{Stability of Pickering Emulsions}

The migration (sedimentation or creaming) and size variation (coalescence or flocculation) of particles in $\mathrm{O} / \mathrm{W}$ emulsions can be easily detected by the Turbiscan (Figure 5). The backscatterings of the emulsion phase formed by GE, GE-TA, and GP-GE-TA were $3.4 \pm 1.0 \%, 76.5 \pm 4.1 \%$, and 98.4 $\pm 1.3 \%(n=3)$, respectively (20 min after the preparation of emulsions). This indicated that the oil droplets coalesced rapidly after the preparation of emulsions and that GED was the poorest emulsion stabilizer. This also suggested the oil droplets generated cannot be fully covered by GED-TA, while oil droplets formed by GP-GED-TA showed the highest stability against coalescence. The backscattering changes in the bottom parts ( $5 \mathrm{~mm}$ above the bottom, for instance) of the $\mathrm{O} / \mathrm{W}$ emulsions stabilized by GP-GED-TA and GED-TA were $2.5 \pm 0.5 \%$ and $27.3 \pm 3.5 \%$, respectively. This indicated the physical stability against coalescence, or aggregation of the oil droplets stabilized by GP-GED-TA, was much higher than those stabilized by GED-TA. Drastic changes in BS profiles were observed between about 33 to $43 \mathrm{~mm}$ and 27 to $42 \mathrm{~mm}$, respectively (Figure 5A,B). This is because the oil droplets creamed at these positions, whereas such changes were not observed in Figure $5 \mathrm{C}$. This suggested that the emulsions prepared with GP-GED-TA exhibited higher stability against creaming than those prepared with GED-TA or GED.

The global TSI values can be used to assess the global stability of O/W emulsions. The higher the TSI value, the less stable the emulsion. The TSI values of the three emulsions increased over time (Figure 6), which indicated the $\mathrm{O} / \mathrm{W}$ emulsions destabilized during storage. However, the order of global TSI is GED $(28.6 \pm 1.5)>$ GED-TA $(19.3 \pm 4.8)>$ GP-GED-TA $(4.4 \pm 1.3)$. Therefore, the GP-GED-TA stabilized emulsion exhibited the highest stability during storage. 

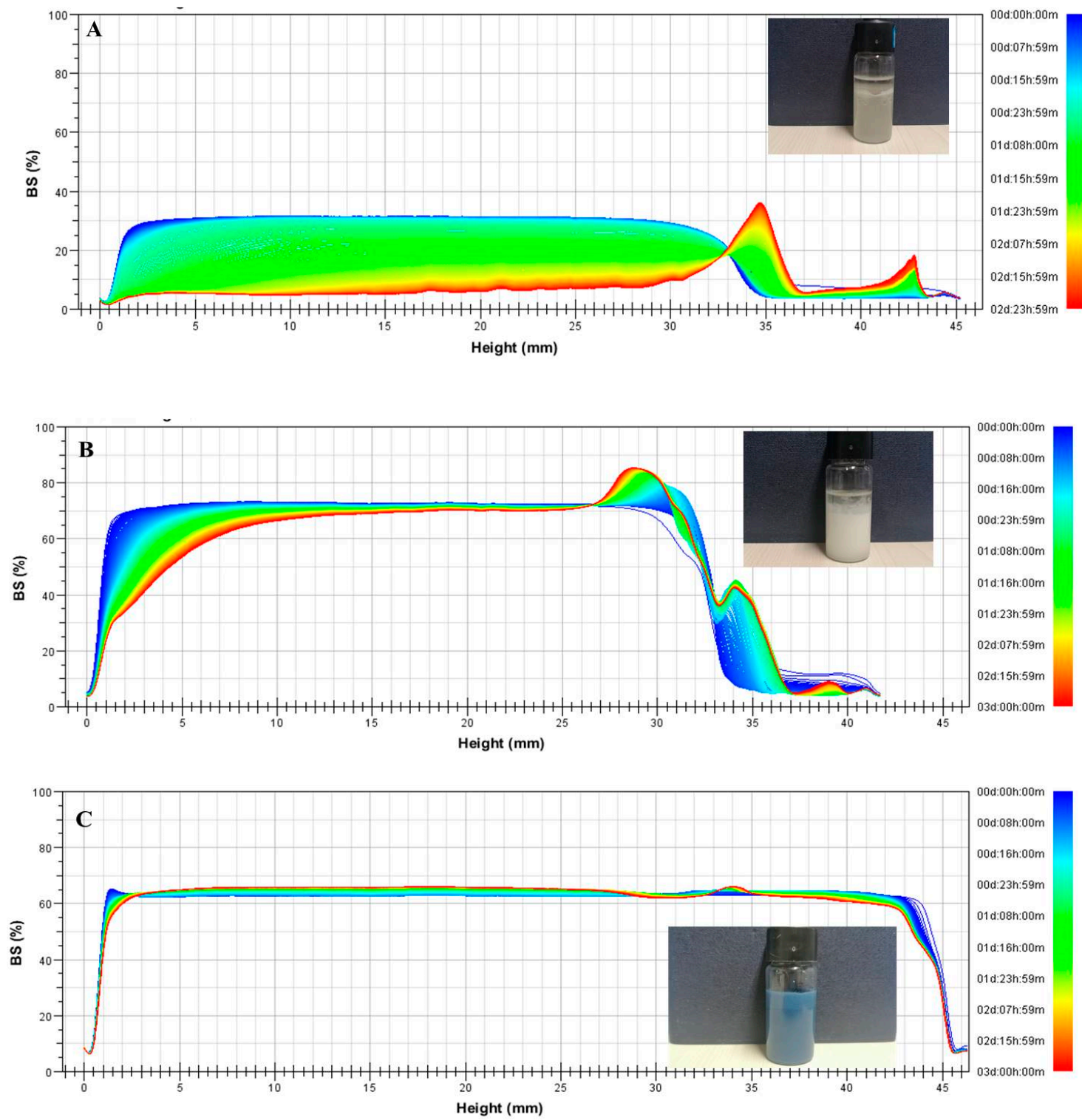

Figure 5. Changes in the backscattering intensity (BS) profiles of oil-in-water $(\mathrm{O} / \mathrm{W})$ emulsions generated by gelatin enzymic digest (GED) (A), tannic acid-induced gelatin hydrolysate (GED-TA) (B), and GP-GED-TA $(\mathbf{C})$. The inserted photographs were taken 3 days after preparation of fresh emulsions.

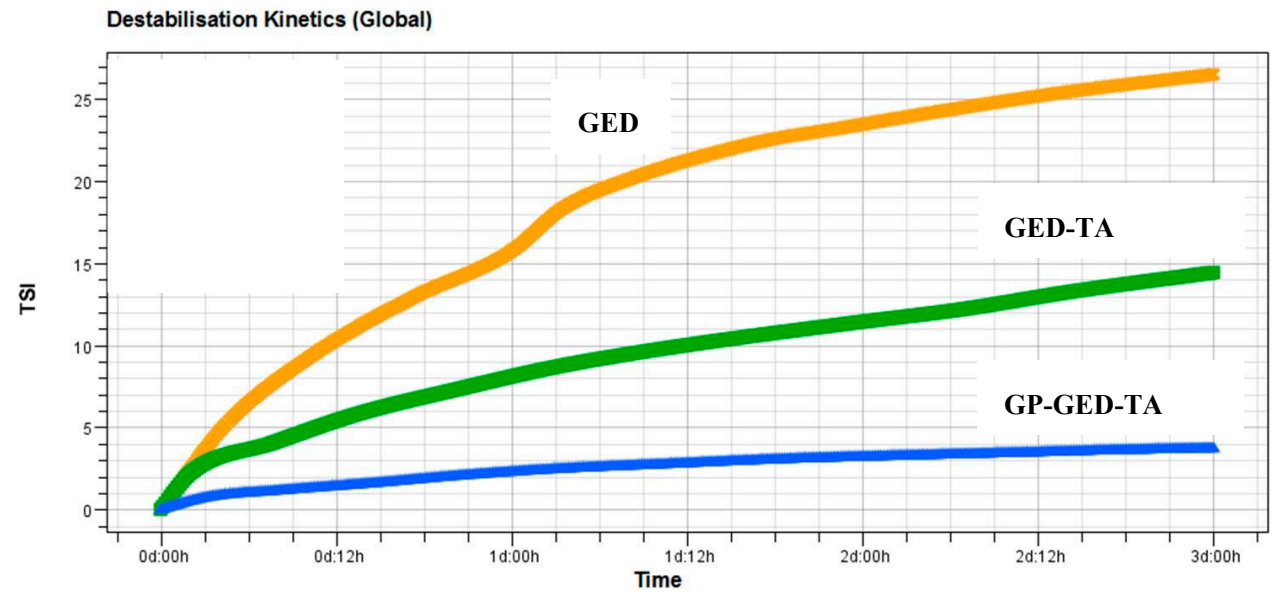

Figure 6. Global turbiscan stability index (TSI) of O/W emulsions generated by different stabilizing agents. 


\subsection{Viscosity and Size Distribution of the Emulsions}

The migration (sedimentation or creaming) of the oil droplets is largely determined by the viscosities of the emulsions and the oil droplet sizes. No significant difference was found between the viscosities of the freshly-prepared emulsions stabilized by GED-TA and GP-GED-TA, respectively (Figure 7A). When the shear rate was 100 (1/s), the viscosities of emulsion stabilized by GED-TA or GP-GED-TA were $3.4 \pm 0.1$ and $3.4 \pm 0.1(\mathrm{~Pa} 1)$, respectively. This demonstrated that the higher stability of the emulsions generated by GP-GED-TA as compared with GED-TA was not caused by the viscosity difference of the emulsions. The emulsions formed by GED-TA or GP-GED-TA exhibited the shear thinning behavior at shear rates of 1 to 1000 (1/s), suggesting formation of a weak network structure in emulsion stabilized by the GED-TA or GP-GED-TA [8].
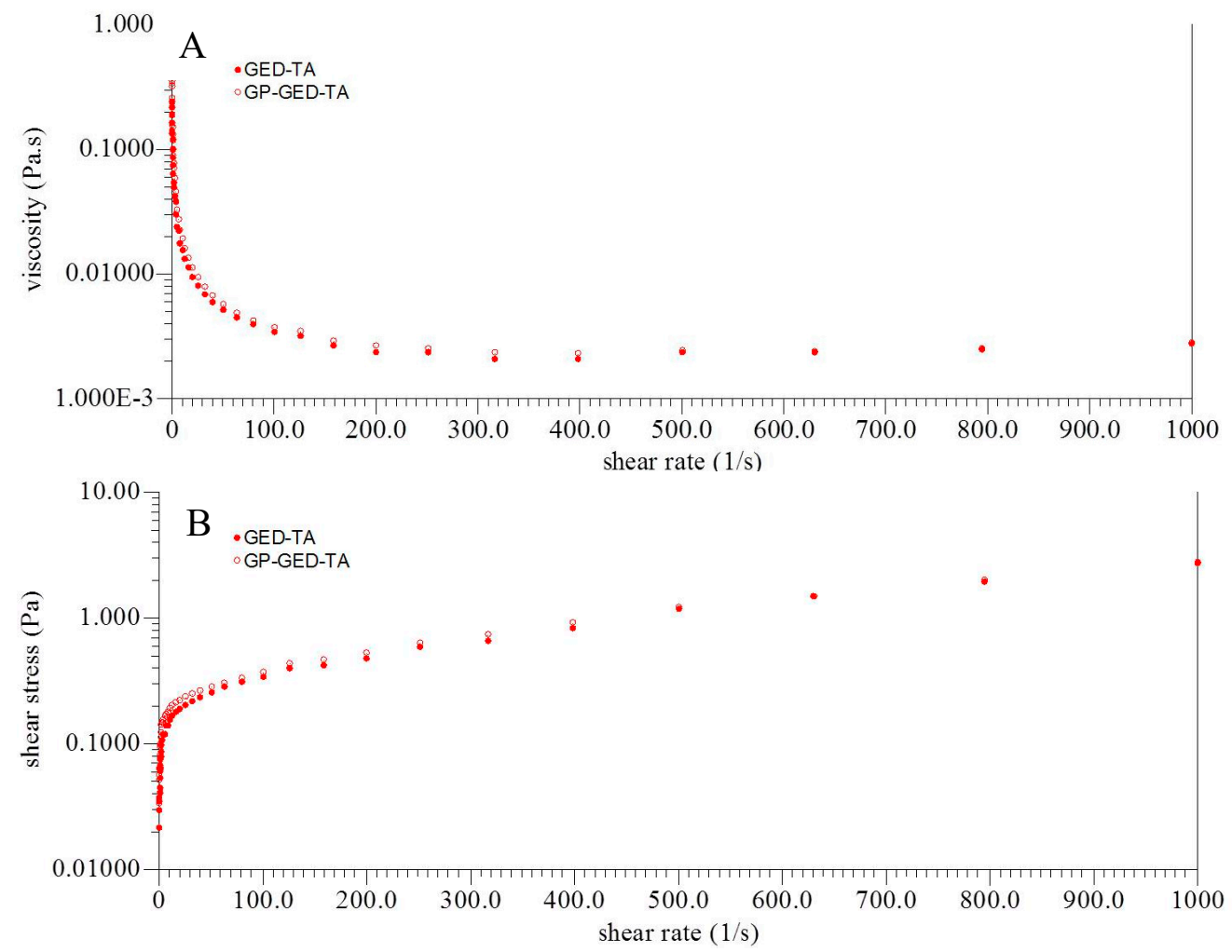

Figure 7. Shear-rate dependence of viscosity (A) and shear stress (B) for emulsions prepared with GED-TA or GP-GED-TA.

The shear stress versus shear rate data are present in Figure $7 \mathrm{~B}$. The data were fitted to the Herschel-Bulkley model $\sigma=\sigma_{0}+\mathrm{K} \cdot \gamma^{\mathrm{n}}$, as shown in Table 1. The $\sigma$ is the shear stress $(\mathrm{Pa}), \sigma_{0}$ is the apparent yield stress $(\mathrm{Pa}), \mathrm{K}$ is the consistency index $\left(\mathrm{Pa} \cdot \mathrm{s}^{\mathrm{n}}\right), \gamma$ is the shear rate $\left(\mathrm{s}^{-1}\right)$, and $\mathrm{n}$ is the flow behavior index. The parameters suggested the emulsion prepared with GED-TA or GP-GED-TA exhibited shear-thinning behavior. This is due to the breaking of polymer networks during shearing, leading to the less intermolecular resistance to flow.

Table 1. Shear-rate dependence of viscosity for O/W emulsion data fitting by the Herschel-Bulkley model.

\begin{tabular}{cccc}
\hline Group & $\boldsymbol{\sigma}_{\mathbf{0}} \mathbf{( P a )}$ & $\mathbf{K}\left(\mathbf{P a} \cdot \mathbf{s}^{\mathbf{n}}, \mathbf{1 0}^{-\mathbf{4}}\right)$ & $\boldsymbol{n}$ \\
\hline GED-TA & $0.09 \pm 0.06$ & $8.55 \pm 2.24$ & $1.17 \pm 0.02$ \\
GP-GED-TA & $0.11 \pm 0.00$ & $6.26 \pm 1.69$ & $1.19 \pm 0.04$ \\
\hline
\end{tabular}

$n=3$ and no significant difference was observed within the same column $(p>0.05)$. 
Oil droplets stabilized by GP-GED-TA were around two orders of magnitude smaller than those stabilized by GED-TA (Figure 8). Three hours after the preparation of emulsions, the volume-weighted mean diameters $\left(\mathrm{D}_{[4,3]}\right)$ of oil droplets stabilized by GP-GED-TA and GED-TA were $1.19 \pm 0.11 \mu \mathrm{m}$ and $108.3 \pm 5.1 \mu \mathrm{m}(n=3)$, respectively, while the corresponding polydispersity indexes (PDIs) were $1.05 \pm 0.01$ and $1.17 \pm 0.26$, respectively. After 60 days of storage, the difference was even larger, the $D_{[4,3]}$ values were $1.18 \pm 0.1 \mu \mathrm{m}$ and $164.3 \pm 19.1 \mu \mathrm{m}$, respectively, while the corresponding PDIs were $1.04 \pm 0.02$ and $1.15 \pm 0.14$, respectively. Therefore, the GP-GED-TA particles exhibited much higher emulsion stabilization than GED-TA.

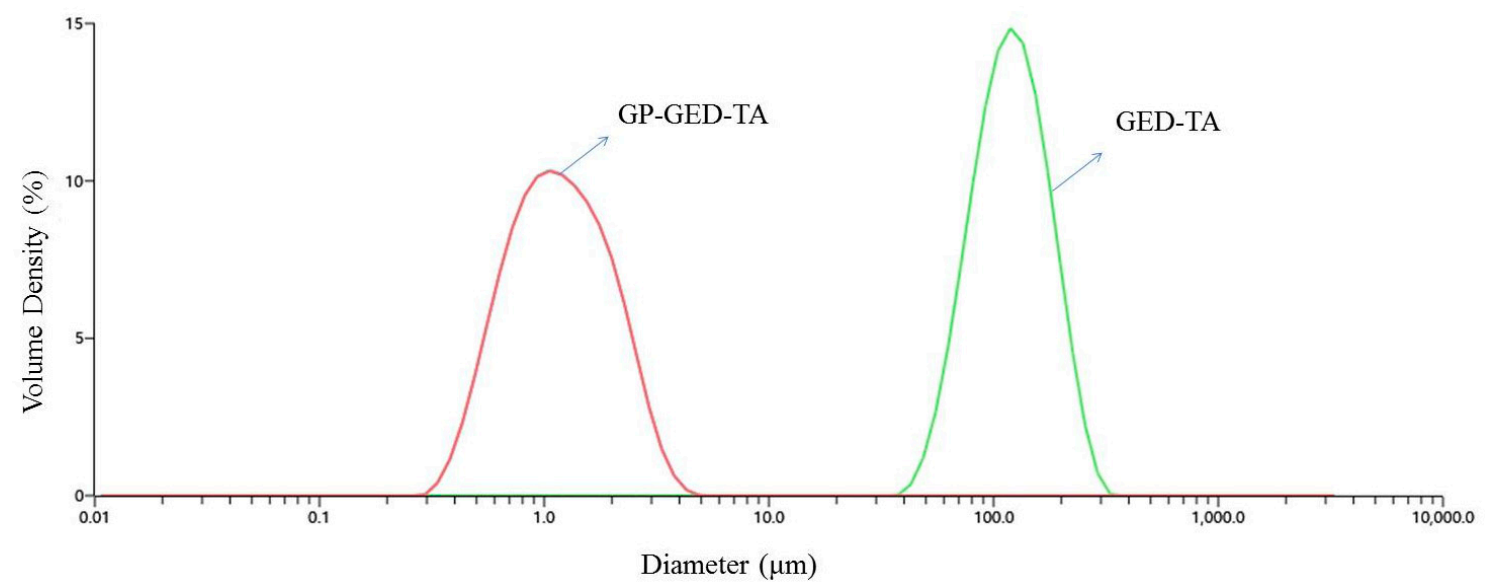

Figure 8. The size distribution curves of oil droplets stabilized by GP-GED-TA and GED-TA.

\section{Materials and Methods}

\subsection{Materials}

GED and TA were from Sigma-Aldrich (St. Louis, MO, USA). Genipin was from Chengdu Jin Taihe Medicinal Chemistry Tech Co., Ltd. (Chengdu, Sichuan, China). Medium-chain triglycerides were bought from Beijing Keao Co., Ltd. (Beijing, China), which contained 65\% caprylic acid and 35\% capric acids. The melting point of MCT is $-13.6{ }^{\circ} \mathrm{C}$. All other chemical reagents used were of analytical grade and from local suppliers.

\subsection{Preparation and Characterization of Gel Particles}

GED was dispersed in deionized water (with $0.02 \%(w / v)$ sodium azide as antibacterial agent) to $2 \% w / v$, on a magnetic stirrer at $300 \mathrm{rpm}$ for $2 \mathrm{~h}$ at $43{ }^{\circ} \mathrm{C}$. To prepare the GED-TA complex particles, $0.3 \mathrm{~g} / \mathrm{mL}$ TA solution was added dropwise into the GED dispersions while stirring. The $\mathrm{pH}$ of the dispersions was kept constant ( $\mathrm{pH} 7.0$ ) with $0.1 \mathrm{~mol} \mathrm{~L}^{-1} \mathrm{NaOH}$ during the addition of TA solution. The final mass ratios of TA to GED were 0 and 1:25, respectively. To crosslink the molecules in the particles, an ethanolic solution of genipin was added to the stirred GED-TA dispersions. The final mass ratio of genipin to GED in each sample was 1:10. The dispersions were stirred for $24 \mathrm{~h}$ at $43{ }^{\circ} \mathrm{C}$, while the $\mathrm{pH}$ was maintained at 7.0 with $0.1 \mathrm{~mol} \mathrm{~L}^{-1} \mathrm{NaOH}$. The dispersions were ultrafiltered with $10 \mathrm{kDa}$ membranes (UFC803096, Millipore, Burlington, USA) to remove the un-crosslinked molecules. The GP-GED-TA samples were freeze-dried to constant weight.

The GP-GED-TA dispersions were prepared by dispersing the freeze-dried GP-GED-TA samples to the concentration of $2 \%(w / v)$, on a magnetic stirrer at $500 \mathrm{rpm}$ for $1 \mathrm{~h}$ at $25^{\circ} \mathrm{C}$. The GED dispersions were prepared by dispersing GED to the concentration of $2 \%(w / v)$. The GED-TA dispersions were prepared by adding $0.3 \mathrm{~g} / \mathrm{mL}$ TA solution dropwise into the $2 \%$ GED dispersions while stirring. The final mass ratio of TA to GED was 1:25 in GED-TA dispersions. The GP-GED-TA, GED-TA, and GED dispersions contained $0.02 \%$ sodium azide. The particle size was determined with a particle analyzer (Nano ZS, Malvern, UK) at $25{ }^{\circ} \mathrm{C}$. The samples were diluted 600 times with deionized water or $8 \mathrm{~mol} \mathrm{~L}^{-1}$ urea 
solution. The viscosity values of water and $8 \mathrm{~mol} \mathrm{~L}^{-1}$ urea urea solutions were 0.8872 and $1.5956 \mathrm{mpa} \mathrm{s}$, respectively. The refractive index values of water and urea solution were 1.330 and 1.399, respectively. The refractive index values and viscosity values for both water and urea solution at given temperatures were choosed directly from the soft package of the particle analyzer. The morphologies of the particles in samples were observed by transmission electron microscopy (TEM, Tecnai-20, Philips, Eindhoven, The Netherlands) at $200 \mathrm{kV}$. Five microliters of GP-GED-TA particle dispersions $(0.01 \%, w / v)$ were deposited onto a carbon-coated grid and dried in air after negative stained with $2 \%$ uranyl acetate. The elastic modulus and force maps were measured by atomic force microscopy (AFM, Dimension, Bruker, Germany) [34]. Samples were diluted 2000-fold with purified water before AFM measurement. Five microliters of the samples were spread onto a mica sheet (one centimeter in diameter) for $10 \mathrm{~min}$ before AFM measurement. During AFM measurement, the scanning rate and peak fore amplitude were $1.98 \mathrm{~Hz}$ and $150 \mathrm{~nm}$, respectively. The following equation was applied to calculate a local reduced elastic modulus [34]. The Derjaguin-Müller-Toporov (DMT) model was applied to fit the data.

$$
\mathrm{F}_{\text {interaction }}=(4 / 3) E^{*}\left(d-d_{0}\right)^{3 / 2}+F_{a d h}
$$

where $\mathrm{F}_{\text {interaction }}$ represented the tip-sample force, $E^{*}$ was the reduced elastic modulus of the tip and the sample, $\mathrm{R}$ was the tip radius, $d_{0}$ was the surface rest position, $d-d_{0}$ was the depth of indentation, and $F_{a d h}$ was the constant adhesion force during the contact.

\subsection{Preparation and Characterization of $\mathrm{O} / \mathrm{W}$ Emulsions}

Medium-chain triglycerides and particle dispersions were mixed at the volume ratio of 2:3. The mixed liquids were sonicated (Scientz-IID, Ningbo, China) at 25\% amplitude for 2 min (working time, $5 \mathrm{~s}$ and rest time, $5 \mathrm{~s}$ ).

The stability of the emulsions was determined with a Turbiscan (Tower, Formulaction, France). Thirty minutes after preparation, the $\mathrm{O} / \mathrm{W}$ emulsions were added into the Turbiscan test specific transparent tubes. The samples were scanned from bottom to top of the tubes over time with a laser $\left(\lambda_{\text {air }}\right.$ $=880 \mathrm{~nm}$ ) for $72 \mathrm{~h}$ at $40^{\circ} \mathrm{C}$. The creaming, coalescence/flocculation of $\mathrm{O} / \mathrm{W}$ emulsions, and Turbiscan stability index (TSI) were calculated from the changes in the backscattered light intensity [38]. The TSI was calculated using the following formula:

$$
T S I=\sqrt{\frac{\sum_{i=1}^{n}\left(x_{i}-x_{B S}\right)^{2}}{n-1}}
$$

where $x_{i}$ is the backscattering for each measurement, $x_{B S}$ is the mean of $x_{i}$, and $n$ is the scan number.

The oil-droplet size of oil-in-water emulsions was measured using a Mastersizer 3000 (Malvern Instruments, Malvern, UK) after 1 and 60 days of storage at ambient temperature $\left(\sim 25^{\circ} \mathrm{C}\right)$. Distilled water $\left(25^{\circ} \mathrm{C}\right)$ was used as the dispersion medium; the refractive index values input was 1.333 . The emulsion was added into the water dropwise. When the laser intensity reached $10 \%$ to $20 \%$, the measurement was started. The mixing speed for the dispersion medium was $2300 \mathrm{rpm}$. The average droplet size was expressed in terms of volume mean diameter $\mathrm{D}_{[4,3]}$ [39]. The polydispersity index (PDI) of oil droplets in emulsions was calculated using the following formula [40]:

$$
P D I=\frac{d_{90}-d_{10}}{d_{50}}
$$

where $d_{10}, d_{50}$, and $d_{90}$ represent the diameter of oil droplets at $10 \%, 50 \%$, and $90 \%$ of cumulative volume.

The viscosity of the $\mathrm{O} / \mathrm{W}$ emulsions ( $1 \mathrm{~h}$ after preparation) was determined using a rheometer (AR1500ex, TA Instruments, New Castle, DE, USA) with a $60 \mathrm{~mm}$ diameter probe [21]. The emulsions were subjected to steady shearing at $25{ }^{\circ} \mathrm{C}$. The points per decade were 10 . Three milliliters of the emulsions were placed onto the plate. The shear rate was set from 1 to $1000 \mathrm{~s}^{-1}$. 


\subsection{Statistical Analysis}

The experiments were performed dependently at least three times. The means and standard deviations (means $\pm \mathrm{SD}$ ) were applied to express the results. Statistical differences were measured by one-way analysis of variance (ANOVA) and $p<0.05$ was defined as significant.

\section{Conclusions}

In this study, edible gelatin enzymatic digest-based hybrid gel particles were fabricated and their ability to stabilize O/W emulsions was evaluated. The GP-GED-TA particles were stable against urea dissociation, due to the covalently crosslinking of the protein network within the TA-induced GED particles. The GP-GED-TA particle was $66.9 \mathrm{~nm}$ in an average hydrated diameter. The GP-GEN-TA particles displayed excellent emulsifying stability against coalescence, aggregation, and creaming (emulsions were stable for at least 60 days) as compared with $\mathrm{O} / \mathrm{W}$ emulsions generated solely with GED-TA particles. It should also be noted that the softness and size of the gel particles and the $\mathrm{pH}$ and ionic concentration of the aqueous phase could also influence the stability of emulsions. We plan to evaluate the effects of these factors in our future work.

Author Contributions: Conceptualization, Z.D.; methodology, Z.D.; software, Z.D.; validation, Z.D., P.W.; formal analysis, Z.D.; investigation, P.W.; resources, P.W.; data curation, P.W.; writing-original draft preparation, Z.D.; writing-review and editing, Z.D.; visualization, P.W.; supervision, P.W.; project administration, P.W.; funding acquisition, P.W. All authors have read and agreed to the published version of the manuscript.

Funding: This research was funded by the National Natural Science Foundation, grant number 31901625.

Conflicts of Interest: The authors declare no conflict of interest.

\section{References}

1. Wei, Z.; Huang, Q. Edible Pickering emulsions stabilized by ovotransferrin-gum arabic particles. Food Hydrocoll. 2019, 89, 590-601. [CrossRef]

2. Sanchez-Salvador, J.L.; Balea, A.; Monte, M.C.; Blanco, A.; Negro, C. Pickering Emulsions Containing Cellulose Microfibers Produced by Mechanical Treatments as Stabilizer in the Food Industry. Appl. Sci. 2019, 9, 359. [CrossRef]

3. Liu, X.; Guo, J.; Wan, Z.-L.; Liu, Y.-Y.; Ruan, Q.-J.; Yang, X.-Q. Wheat gluten-stabilized high internal phase emulsions as mayonnaise replacers. Food Hydrocoll. 2018, 77, 168-175. [CrossRef]

4. Murray, B.S. Pickering emulsions for food and drinks. Curr. Opin. Food Sci. 2019, 27, 57-63. [CrossRef]

5. Dai, L.; Sun, C.; Wei, Y.; Mao, L.; Gao, Y. Characterization of Pickering emulsion gels stabilized by zein/gum arabic complex colloidal nanoparticles. Food Hydrocoll. 2018, 74, 239-248. [CrossRef]

6. Nallamilli, T.; Basavaraj, M.G. Synergistic stabilization of Pickering emulsions by in situ modification of kaolinite with non ionic surfactant. Appl. Clay Sci. 2017, 148, 68-76. [CrossRef]

7. Ma, L.; Zou, L.; McClements, D.J.; Liu, W. One-step preparation of high internal phase emulsions using natural edible Pickering stabilizers: Gliadin nanoparticles/gum Arabic. Food Hydrocoll. 2020, 100, 105381. [CrossRef]

8. Ye, F.; Miao, M.; Cui, S.W.; Jiang, B.; Jin, Z.; Li, X. Characterisations of oil-in-water Pickering emulsion stabilized hydrophobic phytoglycogen nanoparticles. Food Hydrocoll. 2018, 76, 78-87. [CrossRef]

9. Winuprasith, T.; Khomein, P.; Mitbumrung, W.; Suphantharika, M.; Nitithamyong, A.; McClements, D.J. Encapsulation of vitamin D3 in pickering emulsions stabilized by nanofibrillated mangosteen cellulose: Impact on in vitro digestion and bioaccessibility. Food Hydrocoll. 2018, 83, 153-164. [CrossRef]

10. Zhu, Y.; McClements, D.J.; Zhou, W.; Peng, S.; Zhou, L.; Zou, L.; Liu, W. Influence of ionic strength and thermal pretreatment on the freeze-thaw stability of Pickering emulsion gels. Food Chem. 2020, 303, 125401. [CrossRef]

11. Destribats, M.; Wolfs, M.; Pinaud, F.; Lapeyre, V.; Sellier, E.; Schmitt, V.; Ravaine, V. Pickering Emulsions Stabilized by Soft Microgels: Influence of the Emulsification Process on Particle Interfacial Organization and Emulsion Properties. Langmuir 2013, 29, 12367-12374. [CrossRef] [PubMed] 
12. Deshmukh, O.S.; van den Ende, D.; Stuart, M.C.; Mugele, F.; Duits, M.H.G. Hard and soft colloids at fluid interfaces: Adsorption, interactions, assembly \& rheology. Adv. Colloid Interface Sci. 2015, 222, 215-227. [PubMed]

13. Berton-Carabin, C.C.; Schroën, K. Pickering emulsions for food applications: Background, trends, and challenges. Annu. Rev. Food Sci. Technol. 2015, 6, 263-297. [CrossRef] [PubMed]

14. Wang, X.; Zhou, W.; Cao, J.; Liu, W.; Zhu, S. Preparation of core-shell $\mathrm{CaCO}_{3}$ capsules via Pickering emulsion templates. J. Colloid Interface Sci. 2012, 372, 24-31. [CrossRef] [PubMed]

15. Song, X.; Pei, Y.; Qiao, M.; Ma, F.; Ren, H.; Zhao, Q. Preparation and characterizations of Pickering emulsions stabilized by hydrophobic starch particles. Food Hydrocoll. 2015, 45, 256-263. [CrossRef]

16. Lu, X.; Zhang, H.; Li, Y.; Huang, Q. Fabrication of milled cellulose particles-stabilized Pickering emulsions. Food Hydrocoll. 2018, 77, 427-435. [CrossRef]

17. Noguchi, S.; Sato, K.; Yamamoto, K.; Kadokawa, J.-I. Preparation of composite and hollow particles from selfassembled chitin nanofibers by Pickering emulsion polymerization. Int. J. Biol. Macromol. 2019, 126, 187-192. [CrossRef]

18. Zou, Y.; Guo, J.; Yin, S.-W.; Wang, J.-M.; Yang, X.-Q. Pickering Emulsion Gels Prepared by Hydrogen-Bonded Zein/Tannic Acid Complex Colloidal Particles. J. Agric. Food Chem. 2015, 63, 7405-7414. [CrossRef]

19. Sarkar, A.; Murray, B.; Holmes, M.; Ettelaie, R.; Abdalla, A.; Yang, X. In vitro digestion of Pickering emulsions stabilized by soft whey protein microgel particles: Influence of thermal treatment. Soft Matter 2016, 12, 3558-3569. [CrossRef]

20. Xu, Y.; Tang, C.; Binks, B.P. High internal phase emulsions stabilized solely by a globular protein glycated to form soft particles. Food Hydrocoll. 2020, 98, 105254. [CrossRef]

21. Wang, P.; Chen, C.; Guo, H.; Zhang, H.; Yang, Z.; Ren, F. Casein gel particles as novel soft Pickering stabilizers: The emulsifying property and packing behaviour at the oil-water interface. Food Hydrocoll. 2018, 77, 689-698. [CrossRef]

22. Soltani, S.; Madadlou, A. Two-step sequential cross-linking of sugar beet pectin for transforming zein nanoparticle-based Pickering emulsions to emulgels. Carbohydr. Polym. 2016, 136, 738-743. [CrossRef] [PubMed]

23. Ning, F.; Wang, X.; Zheng, H.; Zhang, K.; Bai, C.; Peng, H.; Huang, Q.; Xiong, H. Improving the bioaccessibility and in vitro absorption of 5-demethylnobiletin from chenpi by se-enriched peanut protein nanoparticles-stabilized pickering emulsion. J. Funct. Foods 2019, 55, 76-85. [CrossRef]

24. Ju, M.; Zhu, G.; Huang, G.; Shen, X.; Zhang, Y.; Jiang, L.; Sui, X. A novel pickering emulsion produced using soy protein-anthocyanin complex nanoparticles. Food Hydrocoll. 2020, 99, 105329. [CrossRef]

25. Zhu, X.; Zheng, J.; Liu, F.; Qiu, C.-Y.; Lin, W.-F.; Tang, C.-H. Freeze-thaw stability of Pickering emulsions stabilized by soy protein nanoparticles. Influence of ionic strength before or after emulsification. Food Hydrocoll. 2018, 74, 37-45. [CrossRef]

26. Tan, H.; Zhao, L.; Tian, S.; Wen, H.; Gou, X.; Ngai, T. Gelatin particle-stabilized high-internal phase emulsions for use in oral delivery systems: Protection effect and in vitro digestion study. J. Agric. Food Chem. 2017, 65, 900-907. [CrossRef]

27. Feng, X.; Dai, H.; Ma, L.; Yu, Y.; Tang, M.; Li, Y.; Hu, W.; Liu, T.; Zhang, Y. Food-Grade Gelatin Nanoparticles: Preparation, Characterization, and Preliminary Application for Stabilizing Pickering Emulsions. Foods 2019, 8, 479. [CrossRef]

28. Xiao, J.; Li, Y.; Huang, Q. Recent advances on food-grade particles stabilized Pickering emulsions: Fabrication, characterization and research trends. Trends Food Sci. Technol. 2016, 55, 48-60. [CrossRef]

29. Wu, S.-J.; Ho, Y.-C.; Jiang, S.-Z.; Mi, F.-L. Effect of tannic acid-fish scale gelatin hydrolysate hybrid nanoparticles on intestinal barrier function and $\alpha$-amylase activity. Food Funct. 2015, 6, 2283-2292. [CrossRef]

30. Gerrard, J.A. Protein-protein crosslinking in food: Methods, consequences, applications. Trends Food Sci. Technol. 2002, 13, 391-399. [CrossRef]

31. Wang, L.; Cao, Y.; Zhang, K.; Fang, Y.; Nishinari, K.; Phillips, G.O. Hydrogen bonding enhances the electrostatic complex coacervation between k-carrageenan and gelatin. Colloids Surf. A Physicochem. Eng. Asp. 2015, 482, 604-610. [CrossRef]

32. Huppertz, T.; Smiddy, M.A.; de Kruif, C.G. Biocompatible Micro-Gel Particles from Cross-Linked Casein Micelles. Biomacromolecules 2007, 8, 1300-1305. [CrossRef] [PubMed] 
33. Silva, N.F.N.; Saint-Jalmes, A.; de Carvalho, A.F.; Gaucheron, F. Development of Casein Microgels from Cross-Linking of Casein Micelles by Genipin. Langmuir 2014, 30, 10167-10175. [CrossRef] [PubMed]

34. Xing, R.; Jiao, T.; Yan, L.; Ma, G.; Liu, L.; Dai, L.; Li, J.; Möhwald, H.; Yan, X. Colloidal gold-collagen protein core-shell nanoconjugate: One-step biomimetic synthesis, layer-by-layer assembled film, and controlled cell growth. ACS Appl. Mater. Interfaces 2015, 7, 24733-24740. [CrossRef]

35. Krivosheeva, O.; Sababi, M.; Dedinaite, A.; Claesson, P.M. Nanostructured Composite Layers of Mussel Adhesive Protein and Ceria Nanoparticles. Langmuir 2013, 29, 9551-9561. [CrossRef]

36. Suk, J.W.; Na, S.R.; Stromberg, R.J.; Stauffer, D.; Lee, J.; Ruoff, R.S.; Liechti, K.M. Probing the adhesion interactions of graphene on silicon oxide by nanoindentation. Carbon 2016, 103, 63-72. [CrossRef]

37. Zheng, L.; Jerrams, S.; Xu, Z.; Zhang, L.; Liu, L.; Wen, S. Enhanced gas barrier properties of graphene oxide/rubber composites with strong interfaces constructed by graphene oxide and sulfur. Chem. Eng. J. 2020, 383, 123100. [CrossRef]

38. Leal-Castañeda, E.J.; García-Tejeda, Y.; Hernández-Sánchez, H.; Alamilla-Beltrán, L.; Téllez-Medina, D.I.; Calderón-Domínguez, G.; García, H.S.; Gutiérrez-López, G.F. Pickering emulsions stabilized with native and lauroylated amaranth starch. Food Hydrocoll. 2018, 80, 177-185. [CrossRef]

39. Cabezas, D.M.; Pascual, G.N.; Wagner, J.R.; Palazolo, G.G. Nanoparticles assembled from mixtures of whey protein isolate and soluble soybean polysaccharides. Structure, interfacial behavior and application on emulsions subjected to freeze-thawing. Food Hydrocoll. 2019, 95, 445-453. [CrossRef]

40. Silva, E.K.; Zabot, G.L.; Meireles, M.A.A. Ultrasound-assisted encapsulation of annatto seed oil: Retention and release of a bioactive compound with functional activities. Food Res. Int. 2015, 78, 159-168. [CrossRef]

Sample Availability: Samples of the compounds are not available from the authors.

(C) 2020 by the authors. Licensee MDPI, Basel, Switzerland. This article is an open access article distributed under the terms and conditions of the Creative Commons Attribution (CC BY) license (http://creativecommons.org/licenses/by/4.0/). 